wall had been mechanically injured. Injury to the vessel has been shown by many to result in severe inflammatory conditions. Josué, in 1903, first drew attention to the action of drugs in producing arterial disease in animals. He injected adrenalin into the veins of rabbits and produced extensive changes in the middle coats of the arteries. In man it has often been shown that the first sign of this form of arterial disease is fatty degeneration, and Klotz has suggested that it is this fatty degeneration which is responsible for the attraction and cleposition of calcium salts. In recent years it has been shown by different workers in our Cambridge laboratory that any drug which has the power of considerably raising blood pressure will, when injected into the circulation of healthy animals, bring abont degeneration of the middle coat of the arteries. Generally about six injections must be administered before any changes are observed, and the effects occur alike in young and middle-aged animals. It has been shown that digitalis, squill, apocynum, barium, lead, adrenalin, nicotine, and even the inhalation of tobacco smoke will all bring about these changes. Hence it may be concluded that any considerable absorption of pressor bases from the alimentary canal might give rise to this condition.

The last experiments to which I desire to draw your attention are perhaps the most important-namely, the effect of absorbing small doses of those poisons which are produced in the alimentary canal over a prolonged period. Unfortunately the reliable experiments are not many, but still a number of experiments have been made with some of these amino-bases and have produced remarkable results. Harvey ${ }^{17}$ has noted typical arterio-sclerotic changes in the vessels from administering $p$. hydroxy-phenyl-ethylamine to rabbits whether by the mouth or intravenously, and Etienne ${ }^{\text {s }}$ has observed the same type of effect by using the urohypertensine of Abelous, which, as already pointed out, is probably iso-amylamine.

The plaque formation in the aorta in these cases begins with granular degeneration in muscle fibre. The muscle fibre losing its function tone in the affected portion of the vessel is lost; the blood pressure dilates this somewhat and the elastic fibres lose their crenated form in the middle coat and appear as straight fibres. Considerable leucocytic activity can be observed at this time. Calcium salts are now deposited around the straightened elastic fibres, so that at this stage sections stained in silver nitrate and fixed in sodium hyposulphite show a black band in the substance of the media, whilst the intima may be either quite unaffected or appear a little thickened. The elastic fibres show a normal reaction to elastic stains and do not appear to be in any way affected.

In many of these experiments the heart was found enlarged and exhibited fatty degeneration. In Harvey's experiments the most remarkable changes were found in the kidneys, and these were present both in the experiments in which the drug was injected and those in which it was administered orally. The change consisted in a chronic nephritis showing many similarities to the large white kidney of man. He regards the changes in the kidney as secondary to a vascular sclerosis. The first changes to be produced in such experimental animals are the plaques in the aorta. These are followed or associated with thickening of the walls of the renal arteries, but at this stage without alteration in the glandular substance. Later the reaction of the renal epithelium to stains is impaired and dilatation of some of the tubules and glomeruli becomes evident. This dilatation later may be very marked, and desquamated cells and albuminous material are often observed occupying the dilated lumen; Bowman's capsules are frequently thickened. The tubular epithelium has a ground-glass appearance and the cells are flattened. In more advanced cases round-celled infiltration may be observed round the damaged glomeruli and tubules and freshly formed connective tissue eventually replaces in part the glandular structure. It is a simple matter to produce acute nephritis in animals, but a chronic nephritis of this nature produced by a non-irritant substance is not common and it must be remembered that this may result from the absorption of the amino-base by its natural path, the alimentary canal.

Cambridge.

17 Journal of Pathology and Bacteriology, vol. xvi., 1911, p. 95 p. 105.

\section{CHRONIC INTESTINAL STASIS. ${ }^{\prime}$}

\author{
BY C. H. FAGGE, M.S. LoND., F.R.C.S. ENG.,
} SURGEON TO GUY'S HOSPITAL.

THE purpose of my intervention in this discussion is to support the view for so many years advanced by $\mathrm{Mr}$. Arbuthnot Lane, that in many cases of intestinal toxæmia mechanical factors in the shape of adhesions, bands, or false mesenteries produce kinks with intestinal stasis as their result, and that the operative treatment of these kinks is of the first importance. I have had the unique advantage, which I trust I appreciate, of working in the same wards as Mr. Lane during the past eight years, and during his occasional absence his cases have come under my care. I shall, however, as far as possible speak of opinions gained from my own operative "experience, though I must of course admit that the principles on which my opinions are founded have been gathered from Mr. Lane's practice, and that I was led to take interest in the matter by the success which he has achieved in many cases which I have watched throughout.

I do not propose to found any argument or base any conclusions upon analysis of symptoms or $\mathrm{X}$ ray evidence after giving bismuth. No one can have much experience of abdominal surgery without realising that the conjuring with probabilities which is known as diagnosis is still largely founded on ignorance, for observation at operations has taught us that symptoms apparently suggestive of disease in one organ are often due to disease in another. Even in the present day physicians are too prone to found theories of abdominal pathology on bedside or post-mortem evidence, and to neglect daily opportunities of correcting their beliefs by witnessing abdominal explorations by their surgical colleagues. In no branch of medicine is Sir Berkeley Moynihan's plea for an investigation of the pathology of the living more necessary than in the study of intestinal stasis. $I$ propose to omit $X$ ray diagnosis because I am not competent to construe its findings, though I must admit that in this class of case the advice of an expert is invaluable and it would be ungenerous not to acknowledge that in nearly every case on which I have operated I have gained help from Dr. A. C. Jordan. In no single case has Dr. Jordan's $\mathrm{X}$ ray diagnosis suggested more than I have found at operation, and if I were to grumble it would be that an occasional kink or bound-down ileum has escaped him. I have omitted the above because I want my hearers to understand that my statements and my beliefs are all founded on what I have actually seen during the course of systematic laparotomies, and I may say that except when circumstances were unfavourable I have for several years carried out a thorough routine examination of the parts concerned in this question in every abdomen I have opened for any purpose.

It is fortunate that now the presence of ileal or other bands and kinks is not denied, for there must be many who, like myself, have sufficient personal experience to know that in certain types of case Lane's ileal kink is very commonly met with if it is systematically looked for. I have taken most interest in that class of case which is considered before operation to be either duodenal or gastric ulcer, cholecystitis from gall-stones, chronic appendicitis or ileal stasis, or a combination of any or all of these, and I have therefore paid most attention to those bands and kinks which affect the end of the small and the commencement of the large intestine, though, of course, the rest of the colon has shared with the other abdominal viscera in my routine examination.

I am inclined to think that we may divide cases of intestinal stasis into those which involve the lower ileum and often simulate and probably induce gastric and duodenal disease and those which affect the flexures of the colon; the latter, though peculiarly amenable to surgical treatment by shortcircuiting, do undoubtedly in many cases get along by the aid of medicinal treatment, and under the head of mucous colitis or constipation lead an active life provided they use purgatives or enemata regularly. In advancer cases both types are found in combination. It is interesting historically to note that in his earlier papers Mr. Lane regarded the large

1 A paper read at a special meeting of Fellows of the Royal Society of Medicine on April 21st, 1913, being a contribution to the discussion on Alimentary Toxamia. 
intestine to be the chief source of trouble, taking much the same view of its iniquities as we heard expressed in a paper read at last week's discussion from the medical point of view, and it is only in his publications of the last four or five years that Mr. Lane has ascribed the changes in the large to earlier defects in the small bowel.

The harsh antagonism to Mr. Lane's views has now shifted its ground, and it is most interesting to watch the transition from a denial of the actual occurrence of these bands either to a criticism that the evolutionary view of their causation is inaccurate or to an opinion that if their occasional presence be admitted no symptoms can possibly result therefrom. I share with others a difficulty in comprehending and in accepting in their entirety all Mr. Lane's views as to the pathological conditions which he regards as resulting from ileal stasis, but after many opportunities of actually seeing that his diagnoses before operation were found to be substantiated at the operations, I have verified the fundamental observations in so many of my own operations that $I$ am logically bound to admit that when the basis of his work entirely coincides with one's personal observations on the living, there is every probability that $\mathrm{Mr}$. Lane's farreaching suggestions of etiology and practice may also in course of time prove to be correct.

It is unfortunate that at first the wide question of stasis producing toxæmia was regarded as synonymous with constipation, though this is often but slightly marked in the most toxic patients. It is also to be deplored that Mr. Lane in his earliest papers of 1902 and 1903 did not attach definite names to the abnormal structures he discovered in these patients, for those bands which support the cacum and ascending colon are now widely known as Jackson's veil, who first described them in 1908, while Lane described and actually figured them in his second paper on this subject. ${ }^{2}$

Discussing first the ileal kink, it may occur in two forms : firstly, as a new flat band passing from the right pelvic margin or from the right (originally the left) surface of the mesentery to the adjacent aspect of the ileal circumference and gradually creeping round it until it has reached and bound down the anti-mesenteric border of the bowel. This band typically occurs alone, the appendix is quite free, and probably normal to the naked eye, the proximal ileum ascending from the pelvis is dilated; no better depiction of this condition can be imagined than that of $\mathrm{Dr}$. C. Mayo which Mr. Lane has reproduced in his opening paper. ${ }^{3} \mathbf{I}$ have now seen this type of band kink in such a large percentage of $m y$ cases of duodenal ulcer ( $I$ an sure $I$ am not overstating it at 1 in 3 ) that $I$ cannot believe this association is accidental. I have usually been content to free the ileum by dividing the band and to do a posterior gastro-jejunostomy as $I$ did in the last case I operated on. Even if one upholds the view that the ileal kink causes the duodenal ulcer it does not appear to me illogical to relieve the end-result by the drainage brought about by a posterior gastro-jejunostomy, which is in itself in my experience one of the most satisfactory operations of surgery. In another recent case I operated on a moribund man for a perforated duodenal ulcer, and at the necropsy the kink was found and demonstrated by one of my medical colleagues and by our resident surgical officer.

As yet I have no fixed opinion as to the right treatment of this type of kink. When slightly developed division of the band gives at least temporary relief, but a raw surface has necessarily been produced, and at present we have no sure method by which we can prevent adhesions forming over this area; paraffin and an abdominal support often give much assistance. Then, again, extensive freeing of this band, especially in men, produces considerable disturbance for a few days, probably due to paralytic distension, so that when in doubt as to the safety of dividing a well-marked band it is wiser at once to short-circuit the ileum into the pelvic colon. My small experience coincides with $\mathrm{Mr}$. Lane's, that ileo-colostomy is less dangerous than extensive separation of bands involving the ileum.

In my series of cases this isolated band controlling the lower ileum is commoner than the second type, in which a similar kink is produced by a twisted, narrowed, or kinked appendix adherent near its base to the mesentery, and eventually involving the circumference of the ileum

3 Proceedings of The Lancet, vol. i., 1903, p. 153. p. 75 , fig. 34 . (appendix forming inner limb of parallelogram of Lane). In this class are the cases of stasis which are much benefited by simple removal of the appendix. Dr. C. Mayo's figure, referred to above, well shows another way in which the appendix may be involved, as first described by Mr. Laneviz., by being caught and dragged upwards and outwards by the lowest band passing from the parietal peritoneum on to the ascending colon and cæcum (bands representing the outer limb of the parallelogram of forces of Lane or Jackson's veil). In this type, too, removal of the appendix is beneficial in that appendicular colic or acute inflammation is prevented, but this fails to relieve the greater part of the mischief which is colonic stasis; I have seen several cases bearing out this contention for which ileo-colostomy alone appears, in my opinion, to be effectual.

The duodeno-jejunal band which, according to Lane's view, causes an abrupt kink at that flexure was, I believe, first described by Dr. W.J. Mayo" under the title "Relation of the Meso-colic Band to Gastro-jejunostomy"; it is in teresting to note that so acute a mind did not suspect any causal relationship between this band and the gastric or duodenal ulcer for which presumably gastro-jejunostomy was required. I gather that Dr. Mayo regards this, together with the band suspending the duodenum to the gall-bladder and Lane's ileal band, as congenital in origin.

In the course of this discussion we have been told that dilatation of the duodenum or duodenal kink does not accompany duodenal ulcer; I should like to inquire on what evidence this statement is made, as apparently we are in this instance to accept evidence derived from a bismuth $X$ ray, whereas in the same paper a bismuth $X$ ray of the ileal kink was stated to be unreliable. Only last week a man was sent to me at Guy's Hospital as a case of duodenal ulcer. This was agreed to by one of my medical colleagues and myself as the probable diagnosis after a test meal, yet operation showed no ulcer, but a dilated duodenum and a marked cholecysto-duodenal band was associated with an extensive ileal kink caused by a kinked appendix controlling the ileum. I have seen this dilatation of the duodenum at several operations, just as $I$ have under the same circumstances seen the ileum dilated behind one of the forms of ileal kink.

There is less discussion about the bands which form in relation to the colon. Wilms ${ }^{5}$ described as a congenital variation the "cæcum mobile" which Jackson 6 believes to be secondary to obstruction from membranous pericolitis (Jackson's veil). I have seen these bands, as I have said first described by Lane, on many occasions passing down on the outer side of the ascending colon, and have usually found the cæcum dilated and prolapsed. I have less often met with a band at the splenic flexure, but in most of the cases in which the ascending colon has been involved the right half of the transverse colon has been drawn down parallel to it.

The close association of these conditions would seem to demand a common line of treatment. I do not feel drawn towards the creopexy of Wilms, nor did the operation of crcoplication, which I saw carried out several times last year in the Mayo Clinic, appeal to me as sound, because it can only favour the further descent of the crecum into the pelvis, and does not deal with the bands involving the colon. For this condition short-circuiting of the ileum into the pelvic colon appears to me ideal, and appears to have a brilliant future in cases where medical treatment has failed. If $I$ rightly gathered the gist of the last few sentences of Dr. A. F. Hertz's lucid contribution to this discussion, this view will be a basis of treatment on which medical and surgical opinion will eventually agree. Colectomy will sometimes be required in severe cases or as a secondary operation to shortcircuiting for persistent pain due to reflux into the descending colon.

Now the alternative theories to the evolutionary one of Lane are that these bands are congenital (developmental) or inflammatory in origin, and these alternatives are ably discussed in Jackson's paper to which I have already referred. Can the supporters of the congenital theory point to other instances in the structure of the body in which the abnormality regarded as congenital is hypernormal as such bands must be? Instances of hyponormal congenital abnormalities

5 Archiv für Klinische Chirurgie, 1913, vol. lxix., p. 795. 
(arrests of development) are common enough, but I cannot think of any instance of the converse; yet Dr. W. J. Mayo in a recent paper on the subject? writes: "Lane's kink is undoubtedly also of developmental origin." In a fair number of laparotomies in infants I have seen nothing to support this view.

Again, I cannot believe that bands (a) localised as they often are to the terminal ileum with the appendix free and normal to the naked eye, $(b)$ always passing in the same direction as those which pass down and inwards to the ascending colon, and $(c)$ limited to one aspect of the intestinal circumference, can have an inflammatory origin. I would even go so far as to regard as non-inflammatory some bands in which the appendix was involved, meaning that I have to find evidence that they were due to a subacute or chronic infection spreading from that organ. One has only to examine carefully several of these bands to realise that they are quite unlike in appearance ordinary inflammatory adhesions. My experience has absolutely convinced me that these bands and kinks produce pathological states, as evidenced by abdominal pain, tenderness, loss of weight, tone, and activity, flatulence, constipation, \&c., and from my results in a small number of cases treated since 1908 by separation of bands with or without appendicectomy, ileo-colostomy or colectomy I have sufficient confidence to state as my firm belief that stasis is generally due primarily to a pathological condition of the lower ileum, erolutionary in origin, and that in well-marked cases surgical treatment is required, for $\mathrm{I}$ have seen marked immediate benefit result to these patients, as evidenced by loss of toxæmia and pain, gain in weight, improvement of appetite, and a return of ability to lead and enjoy an active life.

Devonshire-place, $w$.

\section{REMARKS ON}

\section{ABNORNAL INTRA-ABDOMINAL DEVELOP- MENTAL ADHESIONS.*}

BX H. M. W. GRAY, M.B., C.M. Aberd., F.R.C.S. EdIN., SURGEON AND LECTURER OY CLIYICAL SURGERY, ROYAL

INFIRMARY, ABERDEEN; SURGEOA TO THE ROYAL HOSPITAI FOR SICK CHILJREN, ABERDEEN ; AND

WILliam ANDERSON, M.B., Ch.B. Aberd., F.R.C.S. EDIN.

IT is very extraordinary that in this country the subject of developmental adhesions affecting the intra-abdominal viscera has attracted so little attention amongst anatomical and surgical authorities. On the continent, and more especially in America, there has been a remarkable amount of literature produced concerning this subject. We have elsewhere described the more common forms of such adhesions and discussed their etiology, pathological effects, and treatment. In this communication we propose to make a short recapitulation of that paper and to discuss adhesions affecting other parts of the abdomen, as well as what may be called complications of the lesions already described.

It seems to us that Mr. Arbuthnot Lane's work has not by any means been given the consideration which it merits. The inclination has been to regard him too much as a "crank" on chronic constipation or chronic intestinal stasis, while he really deserves the highest praise for having so persistently preached his gospel. All the same, we do not agree with Mr. Lane regarding the etiological significance of these adhesions. Shortly stated, he regards them as the result of intestinal stasis, whereas we regard them as the cause of intestinal stasis. It must be clearly understood that our remarks are confined to a type of adhesion (congenital or developmental) which can be differentiated at operation, usually with ease, from those primarily induced by infective inflammatory processes (acquired). One must remember that these inflammatory or acquired adhesions may produce symptoms identical with those of developmental, and, further, that they may complicate the original developmental adhesions.

7 American Journal of Medical Selence, February, 1913.

* This paper was received several months ago, but owing to its length publication has been delayed.-ED. $\mathbf{L}$.
In the publication referred to we discussed at length the various theories as to the origin of these adhesions, and gave reasons why we came to look upon them as developmental. In a paper published since, $\dagger$ Professor J. M. Flint, of Yale University, has confirmed our theory in every respect. His paper, although published later than ours, was the result of independent observation. He illustrates the mode of formation of these membranes or adhesions in a very clear and convincing manner. Other writers (Frazier, ${ }^{1}$ Coffey, ${ }^{2}$ Blake ${ }^{3}$ ) have independently supported the embryological origin, but in a less definite way. It is manifest that the general tendency amongst the more recent writers is to discard the old explanations, and to incline to the acceptance of congenital or developmental etiology.

We have pointed out that the cause of these abnormal adhesions is what may be termed "excess of physiological fusion." Some critics have objected to this term, and it may be more correct to say that the conditions are due to an "excess of developmental fusion." While most of the abnormal conditions to be considered are due to this excess of developmental fusion, yet some are due to failure of ordinary developmental fusion or to the absorption of membranes which exist in the embryo. This will be pointed out in the course of discussion.

The more we study these developmental membranes and kinks the more are we impressed with the fact that they are in many cases responsible for much ill-health, either directly or by their remote effects, by interference with normal function of various intra-abdominal organs.

(a) Obliterative adhesions of the lesser sac of the peritoneum. - Normally the layers of the gastro-colic omentum are in great part adherent. Similar obliterative adhesions are very frequently found in various parts of the lesser peritoneal cavity and are most evident to the surgeon during the performance of posterior gastro-enterostomy or in cases of gastrectomy. There is no reason to suppose that such adhesions are due to inflammatory processes, because there is no evidence in their neighbourhood of any pathological lesion, nor is there in such cases any history pointing to a previous peritonitis affecting the lesser sac. They are patchy in distribution, and are usually easily separated without causing more than a slight ooze of blood. They apparently do not interfere with the motility of the stomach. They are evidently easily stretched and absorbed because they are very rarely found in cases of dilated stomach. On the other hand, they are fairly frequently found during the performance of posterior gastro-enterostomy where the stomach is not dilated--e.g., in cases of ulcer of the duodenum or lesser curvature. There is no reason to think that they have any causative influence in the formation of such ulcers. They are really only of interest in that, when well marked, they may cause some difficulty in the performance of these operations.

(b) Adhesions affecting the gall-bladder, duodenum, \&.e. (Fig. 1.)-As the gall-bladder buds out from the common duct, it carries with it a fold of the ventral mesogastrium on its under surface. This fold of peritoneum usually becomes absorbed. The membrane, when it persists, varies greatly in its extent and attachments. Above, it may extend so as implicate merely the apex of the gall-bladder; but in well-marked cases may reach as far as the fundus, or even to the under surface of the liver, if the gall-bladder does not reach to the anterior margin thereof. Below and behind, the membrane may blend with the peritoneum ovey the common bile-duct, or be continued on to the anterior surface of the pylorus or duodenum, even becoming continuous with the gastro-colic omentum. as Flint and others have pointed out, and of which condition we have seen several examples. In some of our cases a noticeable "white fusion line" marks the limit of these adhesions. This confirms their congenital origin (see our previous paper). The effect of traction on the gall-bladder may result in a sagging downwards near its junction with the cystic duct. When the patient is in the erect posture complete retention of bile in the gall-bladder may result from this kinking, and, owing to the tension and pressure of the bulging segment on the cystic duct, the gall-bladder may be unable to empty itself. Its spasmodic efforts to do so may cause excruciating pain. In one such case the gall-bladder was in almost $\bar{a}$ gangrenous condition when exposed at operation. It is quite

† Johns Hopkins Hospital Bulletin, October, 1912. 